Relato de Caso

\title{
Tumor desmóide da parede abdominal durante a gravidez: relato de caso
}

\author{
Desmoid tumor of the abdominal wall during pregnancy: a case report \\ Denise Gonçalves Priolli ${ }^{1}$, Carlos Augusto Real Martinez ${ }^{2}$, Décio Luiz Silva Mazzini ${ }^{3}$, \\ Carlos Alberto Fontes de Souza ${ }^{3}$, Helenice Piovesan ${ }^{3}$, Ronaldo Nonose ${ }^{4}$
}

\section{RESUM0}

Tumores desmóides são neoplasias do tecido conjuntivo, caracterizadas por apresentarem crescimento exclusivamente loco-regional, recorrência frequiente e mínimo potencial metastático. Acometem principalmente portadores de polipose adenomatosa familial dos cólons, sendo sua ocorrência isolada extremamente rara. São mais freqüentes nas mulheres em idade reprodutiva e durante a gravidez. Descreve-se um caso de tumor desmóide de grandes proporções, localizado na parede abdominal, que surgiu a partir da $17^{\mathrm{a}}$ semana em gestante sem antecedentes de polipose adenomatosa familial. A neoplasia foi totalmente extirpada utilizando-se prótese de polipropileno para reconstituição da parede abdominal. Atualmente a doente encontra-se bem, um ano após a cirurgia, em uso de antiinflamatório não hormonal para prevenção de recidivas.

PALAVRAS-CHAVE: Fibromatose agressiva/cirurgia; Parede abdominal/patologia; Gravidez

Relato de casos [Tipo de publicação]

\section{ABSTRACT}

Desmoid tumors are neoplasms of the conjunctive tissue that are characterized by exclusive locoregional growth, frequent recurrence and minimal metastatic potential. They mainly affect individuals with familial adenomatous polyposis of the colon, and rarely occur isolated. The single form of this neoplasm most frequently appears in women of reproductive age, and during pregnancy. A case of a desmoid tumor of large proportions located in the abdominal wall is described. It appeared at the 17th week of pregnancy in a woman without any history of familial adenomatous polyposis. The neoplasm was totally extirpated, with the use of a polypropylene prosthesis for reconstitution of the abdominal wall. One year after the surgery, the patient continues to be well, while using non-steroidal anti-inflammatory drugs for the prevention of relapses.

KEYWORDS: Fibromatosis, aggressive/surgery; Abdominal wall/pathology; Pregnancy

Case reports [Publication type]

\section{Introdução}

Os tumores desmóides (TD), também conhecidos como fibromatoses músculo-aponeuróticas, são neoplasias não encapsuladas originárias do tecido conjuntivo, caracterizadas por apresentarem baixo potencial metastático e exuberante crescimento loco-regional, além de elevados índices de recidiva ${ }^{1}$.

Os TD são neoplasias raramente descritas, representando 0,03 a $0,13 \%$ dos tumores de partes moles e a incidência é estimada em 2,4 a 4,3 casos novos por 100.000 habitantes por ano ${ }^{2,3}$. Na maioria dos casos descritos encontram-se associados à polipose adenomatosa familial (PAF), sobretudo na variante clínica denominada síndrome de Gardner, em que, além da polipose cólica, ocorrem concomitantemente

\footnotetext{
Disciplinas de Cirurgia Geral e Anatomia Patológica do Curso de Medicina da Universidade São Francisco - USF - Bragança Paulista (SP) - Brasil. 1 Professor Adjunto da Universidade São Francisco - USF - Bragança Paulista (SP) - Brasil.

2 Professor Adjunto e Chefe do Serviço de Cirurgia Geral do Hospital Universitário São Francisco - USF - Bragança Paulista (SP) - Brasil.

3 Professor Assistente da Universidade São Francisco - USF - Bragança Paulista (SP) - Brasil.

4 Professor Auxiliar de Ensino da Universidade São Francisco - USF - Bragança Paulista (SP) - Brasil

Correspondência: Denise Gonçalves Priolli

Rua São Vicente, 614 - Jardim Paulista - 12947-390 - Atibaia - SP - Tel/Fax: (11) 4412-7730 - e-mail: depriolli@terra.com.br 
tumores cutâneos (lipomas, cistos epidermóides), osteomas, malformações dentárias e retinopatia hiperpigmentada congênita ${ }^{3}$. O aparecimento do TD não associado a PAF é evento extremamente raro $^{4}$. Podem surgir em ambos os sexos e qualquer faixa etária, sendo, contudo, mais freqüentemente descritos nas mulheres em idade reprodutiva e, principalmente, durante a gravidez ou período puerperal $^{5}$.

Apesar de possuírem etiologia pouco conhecida, estudos genéticos recentes em doentes portadores de PAF que desenvolveram TD demonstraram que mutações do gene APC (adenomatous polyposis coli) poderiam não só predispor à formação de pólipos no cólon como também a $\mathrm{TD}^{5}$. A presença de traumatismo tecidual antecedendo o aparecimento do tumor em boa parte dos casos, além da maior incidência dos TD nas mulheres em período de vida reprodutiva ou durante a gestação, sugerem o possivel papel que o trauma tecidual e a estimulação hormonal possam desempenhar no desenvolvimento e crescimento da neoplasia ${ }^{6}$.

O objetivo do presente relato é descrever um caso de TD de grandes proporções, localizado na parede abdominal, que se desenvolveu a partir da $17^{\text {a }}$ semana de gestação em enferma sem antecedentes de PAF, tratado, com sucesso, pela extirpação cirúrgica e terapia preventiva da recidiva com antiinflamatório não hormonal.

\section{Relato do Caso}

Mulher branca, com 26 anos, secundigesta, com antecedentes de cesariana há quatro anos, notou a partir da $17^{\text {a }}$ semana de sua segunda gravidez o aparecimento de tumor localizado na face anterior do abdômen, no hipocôndrio esquerdo, inicialmente de pequenas dimensões e que apresentou crescimento importante no último trimestre de gestação. Deu à luz por meio de cesariana em 30 de abril de 2003, indicada por pós-datismo, a $\mathrm{RN}$ eutrófico pesando $3.860 \mathrm{~g}$. Não foi realizada a ressecção cirúrgica do tumor concomitante ao parto. Apresentou evolução pós-operatória favorável, recebendo alta hospitalar no $3^{\circ}$ dia após o parto. Durante o acompanhamento puerperal houve crescimento acentuado do tumor passando a provocar desconforto e dor à compressão local. Negava antecedentes de trauma abdominal no local do tumor antes ou durante a gestação bem como não possuía antecedente familiar de PAF. Ao exame físico apresentava-se em bom estado geral negando perda ponderal expressiva. Em 27 de novembro de 2003 o exame físico do abdome revelava tumor com
8,0 por 7,0 centímetros de diâmetro, localizado no hipocôndrio esquerdo, que se iniciava três centímetros abaixo do rebordo costal, estendendo-se, no sentido caudal, até a cicatriz umbilical. O tumor possuía consistência firme e mobilidade limitada, sendo doloroso à compressão. A pele que recobria o local encontrava-se preservada, sem sinais inflamatórios ou de infiltração neoplásica.

A radiografia simples do abdome em posição ântero-posterior mostrava opacidade na região correspondente à lesão, sem áreas de calcificação, não permitindo afastar o comprometimento de órgãos da cavidade abdominal. A tomografia computadorizada do abdome demonstrava imagem hipodensa, sólida, arredondada, de contornos regulares, medindo $9,0 \times 7,5 \mathrm{~cm}$, localizada na parede abdominal anterior na topografia do músculo reto abdominal, com preservação da pele e do peritônio parietal, não havendo sinais de extensão para a cavidade abdominal. O tumor provocava compressão extrínseca, deslocando o estômago no sentido posterior. Os demais aspectos tomográficos intra-abdominais eram normais (Figura 1).

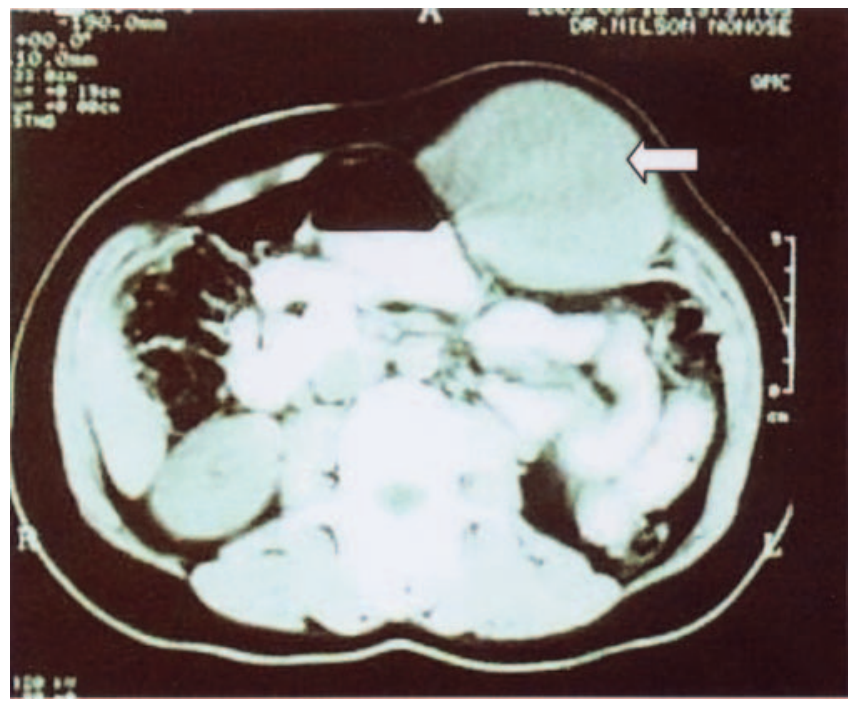

Figura 1 - Tomografia computadorizada do abdome mostrando tumor desmóide localizado na parede abdominal, sem comprometimento de órgãos intra-abdominais, provocando compressão extrínseca do estômago e intestino delgado (seta).

Devido à possibilidade de tratar-se de neoplasia maligna e pelo risco potencial de disseminação, não foi realizada biópsia por punção percutânea, optando-se pela excisão cirúrgica em monobloco, realizada em 4 de novembro de 2003. A ressecção foi realizada por meio de incisão longitudinal, elíptica, englobando pele, tecido celular subcutâneo e o folheto anterior da aponeurose do músculo reto abdominal, que se encontrava es- 
pessado e com aumento da vascularização na região da neoplasia. O tumor foi totalmente extirpado, respeitando-se margem cirúrgica de dois centímetros (Figura 2).

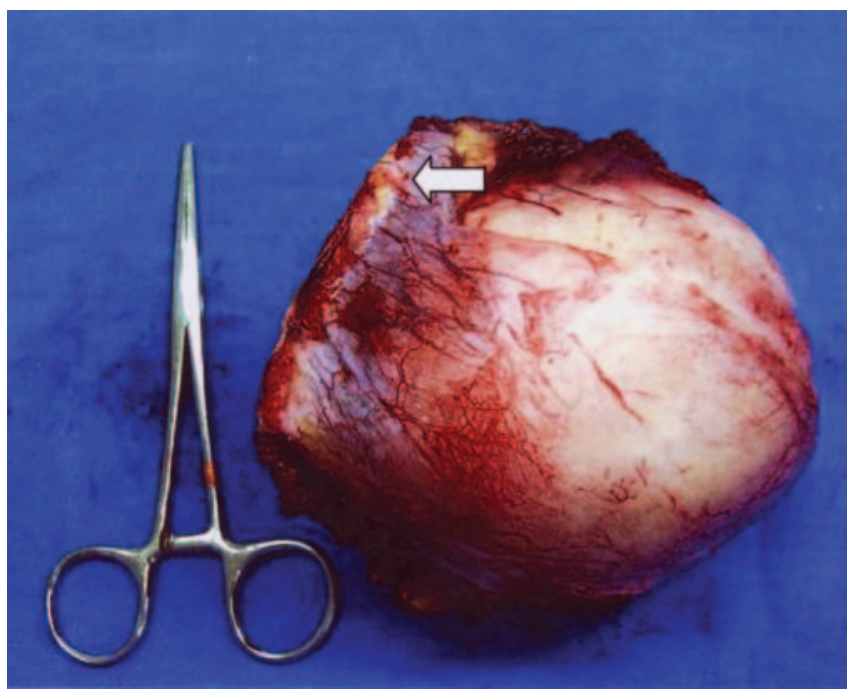

Figura 2 - Produto de ressecção segmentar da parede abdominal anterior revelando tumor desmóide, medindo $10,5 \times 10 \mathrm{~cm}$, localizado entre os folhetos aponeuróticos do músculo reto abdominal. Margens cirúrgicas livres de comprometimento (seta).

O folheto posterior da aponeurose do reto abdominal também apresentava a mesma proliferação vascular, havendo, contudo, nítido plano de clivagem com o peritônio parietal, que não foi seccionado. A extirpação resultou em área de aproximadamente $15 \mathrm{~cm}$ de extensão longitudinal e 10 cm de extensão lateral desprovida de todas as camadas musculares da parede abdominal. Para reconstituição do defeito cirúrgico resultante utilizou-se tela de polipropileno fixada nos folhetos músculo-aponeuróticos remanescentes do músculo reto abdominal, oblíquo externo, oblíquo interno e transverso. Em virtude do extenso descolamento tecidual necessário para fixação da prótese optouse pela colocação de dreno tubular de sucção contínua exteriorizado por contra-abertura.

O exame macroscópico revelou massa nodular, de coloração vermelho-esbranquiçada, consistência firme, desprovida de cápsula, com exuberante proliferação vascular, medindo $10,5 \times 10$ cm e pesando 550 g. À secção longitudinal o tumor era sólido, pardo-esbranquiçado, com áreas centrais de aspecto edematoso e localizado entre os folhetos anterior e posterior da aponeurose do músculo reto abdominal. O exame microscópico demonstrou lesão mesenquimatosa composta predominantemente de células fusiformes em arranjo estoriforme com núcleos pleomórficos e raras figuras de mitose. O interior da lesão, ao contrário da sua zona perifé- rica, apresentava baixa celularidade. Estas células encontravam-se imersas em estroma fibroso com tonalidade basofílica, rico em colágeno e que assumia padrão fibrilar e reticular. Nas regiões mais periféricas a neoplasia mostrava íntima relação com fibras musculares estriadas comprimidas, atrofiadas, e de permeio, tecido adiposo maduro (Figura 3). Diante dos achados pôde-se firmar o diagnóstico de fibromatose extra-abdominal desmóide (tumor desmóide).

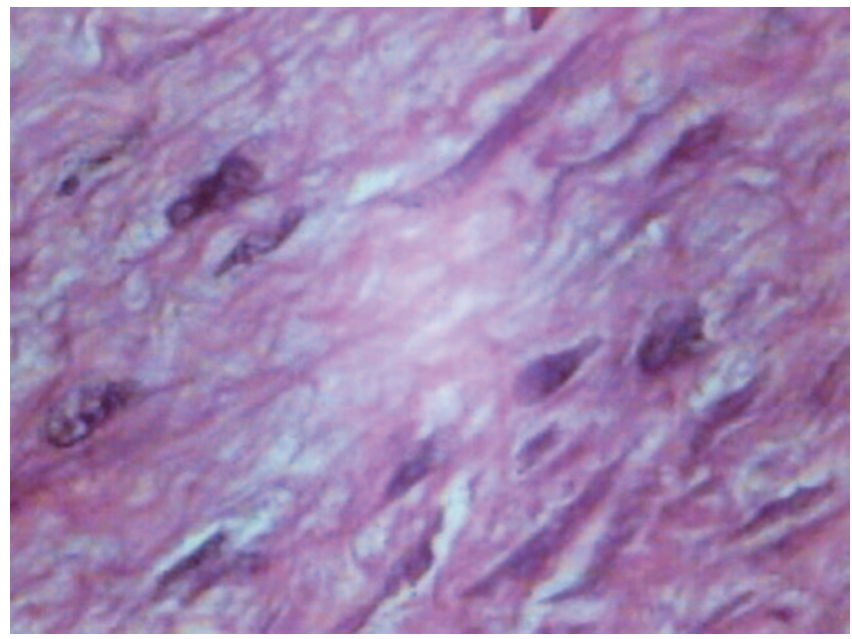

Figura 3 - Fotomicroscopia do tumor desmóide mostrando células fusiformes imersas em estroma rico em fibras de colágeno (HE 400X).

Após a intervenção cirúrgica a doente apresentou evolução satisfatória, tendo recebido alta no $4^{\circ}$ dia pós-operatório, em 28 de dezembro de 2003. A partir do primeiro retorno ambulatorial, com o diagnóstico estabelecido de tumor desmóide, passou a receber anti-inflamatório não hormonal (sulindac) na dose de $400 \mathrm{mg} /$ dia para prevenção de recidivas e omeprazol $40 \mathrm{mg} /$ dia para proteção gástrica. $\mathrm{O}$ antiinflamatório foi mantido na dose inicial por seis meses e a partir de então reduzido para $200 \mathrm{mg} /$ dia. No momento de seu último retorno, em três de fevereiro de 2005, encontravase bem, em uso de sulindac, sem sinais clínicos ou tomográficos de recidiva da doença.

\section{Discussão}

O TD, também denominado fibromatose agressiva ou fibromatose músculo-aponeurótica, é neoplasia originária do tecido conjuntivo das aponeuroses músculo-esqueléticas ${ }^{5}$. Freqüentemente confundida com sarcomas de baixo grau de malignidade, sua denominação deriva-se do grego 
(desmos) pela distribuição tecidual em faixa (estoriforme) que mimetiza os tecidos encontrados nos tendões. Caracteriza-se do ponto de vista evolutivo por não possuir potencial metastático, ter exuberante capacidade de crescimento local com acentuada tendência à invasão de tecidos ou órgãos contíguos, altos índices de recidiva e, curiosamente, pela possibilidade de cura espontânea ${ }^{6,7}$.

São tumores raramente descritos, com incidência estimada de 0,2 a 4,3 por 100.000 habitantes $^{8,9}$. Acometem com maior freqüência portadores de PAF e, em especial, os doentes com sindrome de Gardner, nos quais se desenvolvem em até $20 \%$ dos casos $^{3}$. Caldwell ${ }^{7}$, em 1976, estudando 50.316 espécimes cirúrgicos ressecados, refere que somente pôde observar 17 casos de TD. Entre nós, Speranzini et al. ${ }^{10}$ referem que até 1986 haviam sido publicados 14 casos de TD, tendo acrescentado mais 19 casos em pacientes atendidos no Hospital das Clínicas da FMUSP em período de sete anos. O surgimento da forma esporádica da neoplasia (não associada a PAF) é evento de extrema raridade, com incidência anual estimada entre dois a cinco casos por milhão de habitantes ${ }^{11}$.

De maneira geral os TD acometem preferencialmente o sexo feminino, contudo, quando se analisa sua incidência nas diferentes faixas etárias, verifica-se que ela é significantemente maior durante a fase fértil da mulher, entre a segunda e a terceira décadas. Reitamo et al. ${ }^{3}$, estudando a velocidade de crescimento do tumor em relação ao sexo e à faixa etária em 86 doentes, verificaram que em homens, independente da idade, e nas mulheres, antes da menarca, a velocidade de crescimento do tumor é baixa. Todavia, nas mulheres em idade reprodutiva a velocidade de crescimento do tumor dobra, decaindo rapidamente após a menopausa.

A gravidez também aumenta significativamente o aparecimento dos $\mathrm{TD}^{3-5,7,10-15}$. Speranzini et al. ${ }^{10}$ verificaram que das 14 pacientes estudadas apenas uma não possuía antecedente de gestação. Na maioria das vezes o TD surge durante ou após a segunda gestação (30 a 59\% dos casos), aumentando de tamanho principalmente no último trimestre gestacional, à semelhança da doente do presente relato ${ }^{3,10}$. Com menor freqüência pode surgir no puerpério e, quando isso acontece, geralmente é diagnosticado nos três primeiros anos de seguimento pós-parto ${ }^{5}$. Estes achados sugerem que os hormônios sexuais femininos, particularmente os estrógenos, possam desempenhar papel importante no crescimento deste tipo de fibromatose ${ }^{3,15}$.

Quanto à localização, podem ser divididos em extra-abdominais, abdominais e intra-abdominais, apresentando variações na sua localização segun- do o sexo e a faixa etária ${ }^{10}$. Nas mulheres antes da menarca e nos homens, os TD geralmente são extra-abdominais, ao passo que nas mulheres em idade reprodutiva possuem marcante predisposição pela parede abdominal ${ }^{3}$. Nos tumores de localização abdominal, a parede anterior, e em particular o músculo reto abdominal, é a região mais freqüentemente atingida ${ }^{5,10,11}$. Com relação ao tamanho pode ter dimensões variadas, desde poucos centímetros até tumores de grandes proporções que se estendem para a parede do tórax, podendo invadir órgãos das cavidades abdominal e torácica ${ }^{6,11,14}$.

No passado, diversas teorias foram propostas para explicar a etiopatogenia dos TD e entre elas merecem destaque a teoria traumática e a endócrina ${ }^{8,16,17}$. Na traumática supõe-se que o traumatismo muscular provocado pela distensão da musculatura abdominal decorrente da gravidez, pelo esforço muscular durante o trabalho de parto ou ainda pela incisão cirúrgica levaria à ruptura de fibras musculares. A reação inflamatória necessária para a reparação tecidual se faria de modo desproporcional ao trauma, originando o tumor ${ }^{10}$. O surgimento de TD intra-abdominais em cerca de $20 \%$ dos doentes submetidos a ressecções do cólon para o tratamento cirúrgico da PAF é evidência irrefutável do papel exercido pelo traumatismo tecidual como fator desencadeante da neoplasia ${ }^{3}$.

$\mathrm{Na}$ doente do presente relato não existiam antecedentes de traumatismos abdominais pregressos no local de desenvolvimento do tumor. Sua última gravidez ocorreu quatro anos antes, por cesariana, sem que houvesse desenvolvimento de qualquer anormalidade na incisão cirúrgica. Quando do surgimento do tumor encontrava-se na $17^{\mathrm{a}}$ semana de gestação, período este em que não havia distensão significativa da parede abdominal que pudesse provocar ruptura de fibras musculares. A cicatrização da ferida operatória se fez de modo normal, tendo o TD surgido em região bem distante da incisão cirúrgica. Tais fatos dificultam a hipótese de que o traumatismo isolado pudesse ser imputado como único fator causal.

A maior ocorrência de TD durante a gestação e no período pós-parto, em mulheres em idade reprodutiva, bem como a raridade da neoplasia antes da menarca e após a menopausa fez com que alguns autores sugerissem que o aparecimento do TD poderia estar relacionado à influência tecidual dos hormônios sexuais femininos ${ }^{3,15,16}$. A contagem de receptores estrogênicos no tecido neoplásico obtido de mulheres portadoras de TD é significativamente maior quando comparada ao tecido normal, verificando-se ainda a maior presença de receptores estrogênicos quando comparado aos progestagênicos ${ }^{3}$. O papel dos estrógenos 
no desenvolvimento deste tipo de neoplasia fica corroborado pelas evidências de que mulheres com TD abdominais geralmente possuem, ao longo da vida, maior dominância hormonal estrogênica do que progestagênica. Tais evidências sugerem forte relação entre os níveis de estrógenos e o desenvolvimento dos $\mathrm{TD}^{3}$.

Estudos recentes em doentes portadores de síndrome de Gardner demonstraram a existência de mutações genéticas específicas associadas a maior possibilidade de desenvolvimento dos TD. Existem evidências de que o surgimento da forma isolada da neoplasia (não associado a PAF) também possa estar relacionado a alterações genéticas semelhantes ${ }^{6}$. Na PAF mutações do códon 1444 do gene APC localizado no braço longo do cromossomo cinco em seu exon 15 formam uma proteína APC anômala que teria papel importante no desenvolvimento da doença ${ }^{6,18}$. Dependendo do códon genético onde a mutação ocorre, a expressão fenotípica da doença teria maior ou menor predisposição ao desenvolvimento dos $\mathrm{TD}^{6}$. A presença de deformidades ósseas (exostoses e cistos) em doentes portadores de TD não associados a PAF também reforça esta possibilidade ${ }^{3}$. Tais observações sugerem que possa existir alteração genética prévia nas enfermas que desenvolvem os TD durante ou após a gestação e que fatores como trauma tecidual ou niveis estrogênicos contribuiriam, de forma significante, para o desenvolvimento e crescimento do tumor. Infelizmente, por tratar-se de metodologia restrita a poucos centros, não foi possível realizar o estudo genético no caso descrito no presente relato.

A radiografia simples do abdome é de pouca valia nos TD da parede abdominal, pelas dificuldades em definir precisamente a localização do tumor e o envolvimento de tecidos ou órgãos próximos. A ultra-sonografia do abdome possui melhor acuidade diagnóstica, porém quando comparada à tomografia computadorizada e ressonância magnética apresenta menor precisão na avaliação do comprometimento de tecidos e órgãos vizinhos ${ }^{13}$. Na doente do presente relato a tomografia computadorizada não só permitiu a correta localização do tumor como excluiu o comprometimento de órgãos intra-abdominais.

O exame histopatológico estabelece o diagnóstico definitivo. A biópsia percutânea deve ser evitada pela possibilidade, em caso de sarcomas, de disseminar o tumor no trajeto da punção, optando-se, sempre que possível, pela biópsia cirúrgica com remoção completa da lesão respeitando margens de pelo menos dois centímetros ${ }^{5,19}$. O exame macroscópico geralmente demonstra tumor de consistência firme, desprovido de cápsula, com abundante neoformação vascular na superfície externa. A superfície de corte apresenta características semelhantes às externas, podendo existir áreas de aspecto gelatinoso principalmente no centro do tumor. A microscopia mostra que a neoplasia é constituída de células fusiformes, com pequenos núcleos em fuso distribuídos longitudinal e transversalmente, com raras figuras de mitose, imersas em abundante substância amorfa rica em colágeno ${ }^{7,11}$. Observa-se maior população celular nas zonas periféricas do tumor, enquanto a região central é preenchida por maior quantidade de colágeno. A presença de fibras musculares comprimidas e células gigantes é achado comum nas zonas mais periféricas da neoplasia ${ }^{11}$.

O tratamento de escolha para os TD é a extirpação cirúrgica, que deve ser praticada com amplas margens de segurança. O emprego de biópsia de congelação das bordas ressecadas para confirmar a remoção completa da neoplasia pode ser empregada $^{10}$. Nos tumores de maiores dimensões que necessitem remoção de grande segmento da parede abdominal, à semelhança da doente do presente relato, as próteses cirúrgicas (tela de márlex, polipropileno ou PTFE) podem ser utilizadas ${ }^{10,13,15}$. Nos tumores irressecáveis ou naqueles em que a remoção cirúrgica demonstrar margens comprometidas, a radioterapia pode ser empregada com objetivo de diminuir os altos índices de recidiva.

Drogas antiestrogênicas (tamoxifeno) e antineoplásicas (doxorrubicina, vincristina), imunossupressores (ciclosporina), corticóides (prednisona) e antiinflamatórios não hormonais (indometacina, sulindac) vêm sendo utilizados no tratamento medicamentoso dos TD, com resultados promissores ${ }^{5,11}$. Recentemente tivemos a oportunidade de utilizar o sulindac em doente portadora de síndrome de Gardner que desenvolveu extenso TD de parede abdominal após colectomia total, em que houve remissão completa do tumor um ano após o início do tratamento ${ }^{20}$. Devido aos altos índices de recidiva após a ressecção cirúrgica, que chegam a ocorrer em $45 \%$ dos casos, optou-se, na doente do presente relato, pelo uso do sulindac de maneira preventiva ${ }^{7,12,17,21,22}$. Após um ano de terapia contínua não houve evidências clínicas ou tomográficas de recidiva da doença, confirmando a validade do uso da droga não só no tratamento do $\mathrm{TD}$, como também na prevenção das recidivas.

Apesar da raridade da doença, o obstetra deve estar atento à possibilidade de ocorrência do TD durante o período gestacional, recomendando, o mais rapidamente possivel, a terapia cirúrgica e medicamentosa adequada, evitando com isso o comprometimento visceral e a necessidade de operações extensas com inevitáveis seqüelas estéticas e funcionais. 


\section{Referências}

1. Patel SR, Evans HL, Benjamin RS. Combination chemoterapy in adult desmoid tumors. Cancer. 1993;72(11):3244-7.

2. Chevrel JP, Sarfati E, Saglier J, Kemeny JL. Tumeur desmoid et syndrome de Gardner. A propôs d'une observation. J Chir (Paris). 1983;120(3):159-64.

3. Reitamo JJ, Hayry P, Nykyri E, Saxen E. The desmoid tumor. I. Incidence, sex-, age- and anatomical distribution in the Finish population. Am J Clin Pathol. 1982;77(6):665-73.

4. Gansar GF, Markowitz IP, Cerise EJ. Thirty years of experience with desmoid tumors at Charity Hospital. Am Surg. 1987;53(6):318-9.

5. Diaz-Plasencia J, Cruz Lezcano A, Cisneros Infantas L, Pomatanta Plasencia J, Fonseca Risco G. Tumores desmoides: cuadro clínico y sobrevida. Rev Med Hered. 1998;9(2):69-76.

6. Miyaki M, Konishi M, Kikuchi-Yanoshita R, Enomoto M, Tanaka K, Takahashi $\mathrm{H}$, et al. Coexistence of somatic and germ-line mutations of APC gene in desmoid tumors from patients with familial adenomatous polyposis. Cancer Res. 1993;53(21):5079-82.

7. Caldwell EH. Desmoid tumor: musculoaponeurotic fibrosis of the abdominal wall. Surgery. 1976;79(1):104-6.

8. Dahn I, Jonsson N, Lundh G. Desmoid tumours. A series of 33 cases. Acta Chir Scand. 1963;126(10):305-14.

9. Plukker JT, van Oort I, Vermey A, Molenaar I, Hoekstra HJ, Panders AK, et al. Aggressive fibromatosis (non-familial desmoid tumour): therapeutic problems and the role of adjuvant radiotherapy. Br J Surg. 1995;82(4):510-4.

10.Speranzini MB, Deutsch CR, Martins Júnior O, Cunha JC, Speranzini MM, Oliveira MR. Tumor desmóide: revisão bibliográfica e apresentação de 19 casos. Rev Hosp Clin Fac Med Univ São Paulo. 1988;43(1):14-9.
11.De Cian F, Delay E, Rudigoz RC, Ranchère D, Rivoire M. Desmoid tumor arising in a cesarean section scar during pregnancy: monitoring and management. Gynecol Oncol. 1999;75(1):145-8.

12. Rocco R, Santos AS, Suassuma E. Tumor desmóide: fibroma muscular abdominal subaponeurótico em pós-cesárea. J Bras Ginecol. 1988;98(1/2):53-5.

13. Barros ACSD, Barros VV, Carvalho FM, Zugaib M. Tumor desmóide após laqueadura tubária puerperal. Rev Ginecol Obstet. 1990;1(1):80-2.

14. Knightly JJ, Machiedo GW, Merk EA, Blackwood JM. Giant recurrent desmoid tumor: a case report. Am Surg. 1977;43(9):613-6.

15. Durkin AJ, Korkolis DP, Al-Saif O, Zervos EE. Fullterm gestation and transvaginal delivery after wide resection of an abdominal desmoid tumor during pregnancy. J Surg Oncol. 2005;89(2):86-90.

16. Musgrove JE, McDonald JR. Extra-abdominal desmoid tumors: their differential diagnosis and treatment. Arch Pathol. 1948;45(4):513-40.

17. Coelho JCU, Widerkehr JC, Campos ACL, Camargo Júnior CA, Brenner S. Diagnóstico e tratamento do tumor desmóide abdominal. Rev Col Bras Cir. 1992;19(2):74-6.

18. Hartley JE, Church JM, Gupta S, McGannon E, Fazio VW. Significance of incidental desmoids identified during surgery for familial adenomatous polyposis. Dis Colon Rectum. 2004;47(3):334-40.

19. Lopes Filho GJ, Carvalho SMT, Scalabrini M, Ricca $\mathrm{AB}$, Sato NY. Lipossarcomas abdominais. Rev Assoc Med Bras. 1995;41(3):219-26.

20.Sportiello DJ, Hoogerland DL. A recurrent pelvic desmoid tumor successfully treated with tamoxifen. Cancer. 1991;67(5):1443-6.

21. Martinez CAR, Priolli DG, Schmidt KH, Caltabiano C, Andreatta MFS, Gimenez M. Eficácia no uso do sulindac no tratamento do tumor desmóide na sindrome de Gardner: relato de caso. Rev Bras ColoProctol. 2004;24 Supl 1:64-5.

22. Reitamo JJ. The desmoid tumor. IV. Choice treatment, results, complications. Arch Surg. 1983;118(11):1318-22. 